\title{
Numerical Evaluation on Improvement Performance of Waved Connection to Reduce Damage on Buried Gas Pipeline
}

\author{
Seyed Mohammad Seyed Kolbadi $(\mathbb{D}$, Nemat Hassani, and Mohammad Safi $\mathbb{D}$ \\ Department of Structure and Earthquake Engineering, College of Civil and Environment Engineering, \\ Shahid Beheshti University, Tehran, Iran \\ Correspondence should be addressed to Mohammad Safi; m_safi@sbu.ac.ir
}

Received 31 October 2020; Revised 19 November 2020; Accepted 7 December 2020; Published 22 December 2020

Academic Editor: Masoud Mirtaheri

Copyright (c) 2020 Seyed Mohammad Seyed Kolbadi et al. This is an open access article distributed under the Creative Commons Attribution License, which permits unrestricted use, distribution, and reproduction in any medium, provided the original work is properly cited.

\begin{abstract}
One of the major challenges for the oil and gas industry is to keep buried metal pipes safe from faulting. This paper discusses about a solution to keep buried pipes safe. In this study, after examining the different dimensions of the effect of wave connection on improving the performance of buried metal pipes, by changing the geometric shape of the wave connection such as doubling it, the behavior of the pipe is greatly improved. Waved connections, by their local deformation, create a rotational joint in a limited area so that other parts of the pipe remain intact. In this paper, the behavior of buried pipes due to slip direction fault displacement by modelling with Abacus software version 2017 and selection of 4-node shell element and 8-node shell element have been used for pipe and soil modelling, respectively. In this paper, by comparing to a single waved connection with a double waved connection, the performance of the pipe due to the faulting phenomenon was evaluated. The results show the improvement of the excellent performance of the double joint by reducing the plastic strain values. In addition to increasing the ductility of the pipe, the double connection has been able to reduce the strain values by about $50 \%$ compared to the single connection. In general, this paper shows that the use of wave connections can significantly increase the level of safety of buried gas pipelines without increasing the cost.
\end{abstract}

\section{Introduction}

Many studies have been conducted on the behavior of pipes at fault intersections. Newmark and Hall [1] (pipe intersection with active fault) are the first to analytically calculate the pipe wall stress by considering the cable model and the plate fault under small displacements. Kennedy et al. [2, 3], with the expansion of the previous work, developed analytical models, also taking into account soil and pipe interactions. Wang and Yeh [4] were able to improve this methodology for bending stiffness of pipes. Vegiokas et al. [5] should also publish their research using the theory of beams on the elastic bed and also the effect of both horizontal and vertical fault displacements. Urock and McCaffrey [6] and Dismad et al. [7] studied the distribution of strain on interrupted pipes by faults based on gas and water pipes' performance in the San Fernando earthquake. Wang [8] developed the theory of beam on an elastic bed. Takada et al. [9] also proposed a more simplified method for a more accurate evaluation of critical strain of steel pipes interrupted by faults using the relationships between the pipe's axial deformation and the transverse deformation. Recently, Karamitros et al. [10] improved the previous analytical achievements by combining the beam model on the elastic bed and the elastic beam theory to estimate the maximum strain due to strike-slip and normal faulting. Trifono and Cherini $[11,12]$ presented a quasianalytical methodology for pipe stress-strain analysis considering the ratio of transverse to axial displacements.

In general, the behavior of buried pipelines depends on many parameters like underground water surface. Recently, Bouatia et al. [13] investigated about the structural behavior of pipelines buried in expansive soils under rainfall infiltration. In that paper, numerical analyses were performed to investigate the transverse structural behavior of buried pipelines in expansive soils considering the unsaturated behavior of soil under the effect of $4 \mathrm{~mm}$ /day rainfall precipitation lasting for 30 days as an external hydraulic 
loading. Considering the water supply $800 \mathrm{~mm}$ pipeline coming from the Beni-Haroun Dam [14] and buried at $2 \mathrm{~m}$ depth in Aine-Tine (Mila, Algeria) [15] high expansive soil, four simulations were performed to demonstrate the effect of the initial suction profiles which may represent different degrees of aridity that characterize regions with arid and semiarid climate. The study highlighted that the unsaturated behavior of expansive soils because of their volume instability is very sensitive to climatic conditions and can exert adverse effects on pipelines buried within such soils. As a result, consistent pipeline design should seriously consider the study of the effect of the climatic conditions on the overall stability of the pipeline structure. Also, various numerical simulations have been performed on the behavior of the pipe on the soil bed. Abbas Haghollahi et al. [16] studied about behavior of connection between steel I-beam and H-column when affected by cyclic loading. They found that reinforcement with a vertical triangular rib plate attached to the top and bottom flange plates can improve cyclic behavior of WFP connections.

According to the results of previous research, in general, the mechanism of pipe failure can be classified into three modes: tensile damage, shear damage and, most importantly, compressive damage (buckling damage). In this regard, we seek to provide a solution in conventional metal pipes that can minimize the mentioned damage and increase the pipes' service life.

Joshi et al. [13] used pipe modelling as a beam to investigate pipelines' behavior facing the faults. Okan et al. [14] also presented a simplified beam-based model as a useful and efficient tool for calculating the critical length of a pipe and the methodology for forming a pipe failure curve. This model has also been implemented and used in common international standards as an effective and reliable computational modelling approach, including Euro Code 8 [15], ALA [16], and ASCE. Vozuras et al. [17] also presented the exact finite element model for the pipeline in the face of the fault phenomenon. In this model, soil properties and pipe passage angle from the fault and mechanical properties of the pipeline are used to express the critical buckling strain. This model was also used by Zhang et al. [18] and Trifonov [12] to study the effects of trench dimensions, soil intrinsic properties, and fault motion simulation.

The behavior of steel pipes under pressure and buckling is very complicated. Hence, a case study on pipe wall failure is quite essential to understand transmission lines' actual behavior in the face of displacement caused by faults. Many researchers have considered the behavior of steel pipe in the face of compressive loading. Reed [19], and more recently, Tutunsa [20] as well as Brady [21] and Kirikidis and Joe [22] evaluated the buckling failure of steel pipes in the face of axial net pressure and flexural behavior. Caramanus and Tassoulas [23] also recently studied the behavior of large diameter pipes that are welded in a spiral. Besides, the effect of peripheral soil on the buckling strength of buried pipes has been investigated by Jon and Kirikides [24].

So far, many studies have been conducted on the behavior of buried pipes due to faults, but few studies have been conducted to provide a practical solution to keep buried pipes safe. Challenges of buried pipes against faulting phenomena include high deformation, high axial strain rate, crimping of pipe cross-section, and local buckling. Using a wave connection can be a good solution to solve these problems. A recent wave connection solution by Packer Wham et al. [25] has been proposed, but this approach only refers to the study of large axial displacements. In the present paper, after examining different dimensions of the effect of wave connection on improving the performance of buried pipes cross-slip fault, for the first time, the geometric characteristics including doubling the wave connection have been improved [26]. This solution can be a safe, practical, inexpensive, and attractive solution for oil and gas industry employers. Due to the fact that the cross-section of the pipe in the fault zone remains unchanged after the fault is displaced, so after the fault is displaced, the pipe can continue to serve [27].

\section{Materials and Methods}

2.1. Buckling Model including Force-Displacement Characteristics of Soil. The strongest argument for the claim that the nonlinear force-deformation details of the soil significantly affect the starting buckling of the buried pipe was studied by Turgard and Needelman [28]. In simple conditions, the soil is modelled elastically and applies lateral force to the pipe. This force per unit length is equivalent to a spring with a constant stiffness $k$. In this case, the following equation is valid.

$$
E I y^{\prime \prime \prime}+P y^{\prime \prime}+W=0
$$

where $E$ is the modulus of elasticity, $I$ is the inertia moment, $y$ is the beam response, and $w$ is the equation constant. The $P$ parameters also can be driven by equation (2). It is simple to show (for example, reference [29]) that the critical buckling load is obtained from the following equation.

$$
P=2 \sqrt{\mathrm{kEI}} \text {. }
$$

2.2. Critical Buckling Stress Caused by Bending Moment. The buckling of pipes occurs when the stress exceeds the yielding stress of the material. Due to the strike-slip fault, the bending moment due to the fault's displacement causes the buried pipe to bend. Many approximate relationships explain the amount of buckling stress and moment created in the pipe under bending, without considering the internal pressure. One of the pioneers of these efforts in the nonlinear structural analysis was performed by Brazier [30]. He found that pipes break down when the deformed inner radius of the pipe reaches the pipe's diameter. The $M_{\mathrm{crl}}$ bending moment is calculated based on this type of deformation based on the following.

$$
M_{\mathrm{crl}}=\frac{\sqrt{2}}{9} \frac{E \pi D t^{2}}{\sqrt{1-v^{2}}} .
$$

$D$ is the pipe's diameter, $t$ is the thickness of the pipe, $E$ is the modulus of elasticity, and $v$ is the Poisson's ratio. The 
maximum flexural stress of the pipe under the $M_{\text {cr }}$ buckling moment can be expressed as follows.

$$
\sigma_{\mathrm{crl}}=\frac{4 M_{\mathrm{cr}}}{\pi D^{2} t}
$$

If the critical buckling stress of the pipeline under bending is similar to the buckling stress of a pipe under uniform pressure, the buckling stress is expressed as follows:

$$
\sigma_{\mathrm{cr} 1}=\frac{2 E}{\sqrt{3\left(1-v^{2}\right)}}\left(\frac{t}{D}\right) .
$$

Then, the buckling moment is extracted as follows:

$$
M_{\mathrm{cr} 2}=\frac{E \pi D t^{2}}{2 \sqrt{3\left(1-v^{2}\right)}} .
$$

Tymoshenko and Gear [31] stated that the maximum compressive stress in the critical buckling moment is about $30 \%$ higher than that obtained from equation (6):

$$
M_{\mathrm{cr} 3}=0.65 \frac{E \pi D t^{2}}{\sqrt{3\left(1-v^{2}\right)}} .
$$

These theories are not based on internal pressure. Based on the plastic theory, numerical solutions for stress and strain components are obtained for normal pipe pressures by $\mathrm{Hu}$ and Yuan [25]. The internal stress and strain distribution of the pipe can be obtained by formulas. But they did not investigate the buckling problem. Bending deformation of buried pipes is a nonlinear problem. The bending moment is not uniform along the axis of the pipe. Soil-pipe interaction is also an important factor for buckling behavior. Besides, the pipe is a thin shell structure. When large deformations appear on the pipe's cross-section, the superposition principle cannot be used for axial strain and flexural strain interactions. There may also be residual stress and stress concentration for the pipes; therefore, it is difficult to solve the pipe response by the analytical method. The finite element method will be more appropriate.

Because the buckling of pipes due to its geometric characteristics can occur local buckling off the plate on its wall, the study of its behavior will be quite complex analytically. Therefore, for a more detailed study of this issue, the finite element method has been used, and Abacus software has been used for simulation. As shown in Figure 1, the fault's motion depends on the two angles of the fault slope and the pipe's cross-sectional angle, which are presented in the vertical and horizontal planes, respectively [32].

In this paper, to focus more on expanding the application of waved connection on the performance of buried gas pipes under the influence of slip directional fault motion, the same values of $\beta$ and $\phi$ are considered equal to $90^{\circ}$. These parameters are equivalent to the angle of the pipe with the fault plane and the direction of the pipe with the fault direction, respectively.

So far, many studies have been conducted on the behavior of buried metal pipes crossing faults. But very few

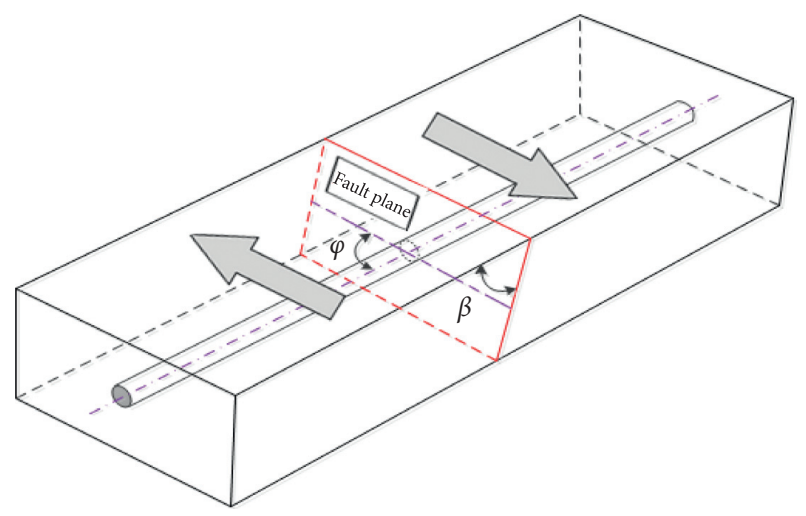

Figure 1: Geometric view of pipe crossing fault.

solutions have been proposed to keep buried pipes from fault displacement safe. These solutions must address challenges such as increasing the longitudinal strain rate, pipe cross-sectional crunch, and local buckling. On the other hand, the solution must be a cheap and reliable application to attract the attention of employers in the oil and gas industry. Wave connection can provide a good cover to solve these problems. Although the wave connection solution recently developed by Packer Wham et al. [33] is given, this study merely examines large axial displacements. In the present paper, after evaluating the performance of the wave connection for the first time, by significantly changing the geometric shape of the connection and converting it to a double connection, a significant improvement in the behavior of the buried pipe is evaluated.

\subsection{Numerical Analysis}

2.3.1. Validation. Packer Wham et al. [34] studied an experimental investigation to evaluate the axial performance of waved connections (Figure 2). In this laboratory study, by applying a large axial displacement by the actuator to a steel pipe with a $20 \mathrm{~cm}$ diameter that waved dy $20 \mathrm{~mm}$ radius, modulus of elasticity of $217 \mathrm{GPa}$, and yielding stress of $309 \mathrm{MPa}$, strain data were recorded by strain gauges and displacement.

In this paper, to verify the numerical model, the experimental and numerical results were compared together. Figure 3 shows 5 steps of compressive force that have been compared with experimental results).

The results show that they are qualitatively consistent with each other. For a quantitative comparison of the laboratory model results and the numerical model results, the values of axial force of the pipe were compared with each other (Figure 4).

As shown in Figure 4, the numerical model results are in good agreement with the laboratory results, so other results of the numerical model can be an acceptable evaluation criterion by comparing the numerical and laboratory results. The numerical model can be obtained to simulate the trend of changes in compressive force against displacement and axial strain against displacement. 


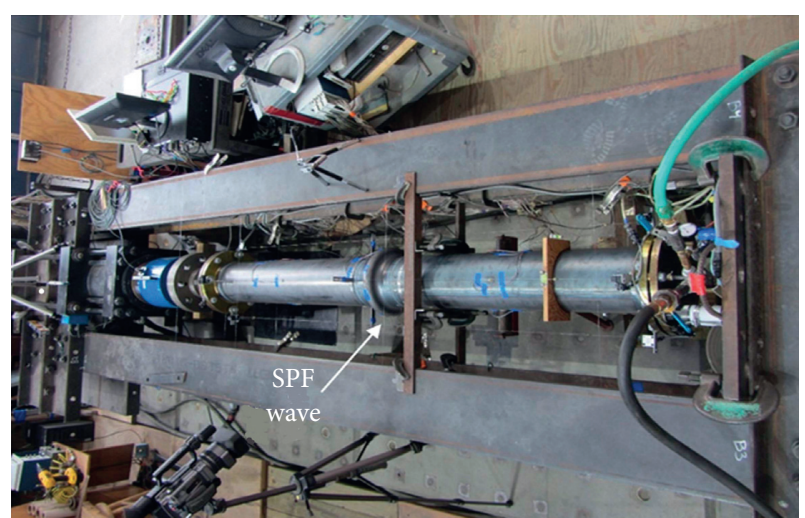

FIGURE 2: Experimental test of axial compressure of the pipe with waved connection [34].

\subsubsection{Evaluation of Waved Connection Performance on Pipe} Performance. So far, the numerical model of the waved connection has been validated based on the experimental model of Packer Loan, and the accuracy of its results can be cited. The depth of the pipe's burial is two times its diameter, which is in accordance with the pipeline engineering method [35] and the length of the pipe and the surrounding soil. According to the results obtained in this paper, $200 \mathrm{~m}$ is equal to 218 times the diameter of the pipe as the optimal length. In the $y$ and $z$ directions, according to the recommendation of Vozoras [17], 6 and 10 times the diameter of the pipe are considered, respectively. The pipe diameter is $D=0.914 \mathrm{~m}$, and the thickness is $t=8 \mathrm{~mm}$, which is the conventional size of gas transmission pipelines (Figure 5).

Two static analysis steps are applied sequentially. First, the force of gravity is applied to the soil and the pipe's internal pressure, and then, the transverse displacement is applied to one of the fault blocks. The degrees of freedom related to the boundary plates, including the lower plate and the side plates of the first block, are fixed, and the second block is uniformly displaced in the lateral direction. According to the proposal of Vozoras et al. [17], the mechanical properties of the soil are considered as elasticperfectly plastic with the Mohr-Coulomb model, which includes internal friction angle $\varphi=0^{\circ}$, cohesion $C=50 \mathrm{kPa}$, Poisson ratio $\nu=0.3$, and elastic modulus $E=25 \mathrm{MPa}$. Also, the appropriate coefficient of friction angle, in this case, is considered $\mu=0.5$.

The results obtained for API 5L [36] are X65 rank of steel pipelines. The stress-strain diagram for the steel materials of gas pipes is traditionally considered equal to X65 steel pipelines. The yielding stress is $\sigma_{y}=448.5 \mathrm{MPa}$, the modulus of elasticity is Gpa210, Poisson's ratio is 0.3 , and the density is $7800\left(\mathrm{~kg} / \mathrm{m}^{3}\right)$. Additionally, the reliability coefficient of 0.72 and the maximum operating pressure $P_{\max }$ of these pipelines have been obtained according to the relationship $[37,38]$, where $\sigma_{y}$ and $P_{\max }$ are the yielding stress and maximum operating pressure, respectively.

2.3.3. Waved Connection Performance. To better understand this issue, Figure 6 diagrams are used to compare the plastic strain values in the critical areas of two straight and waved pipes.
According to Figure 6, the pipe's plastic strain values with waved connection are two times higher than the straight pipe. But in the critical area, the pressure is much lower. Besides, plastic strain values in the most critical compression area of the straight pipe are about four times higher than the plastic strain values in the same area of the pipe with a waved connection. In other words, by eliminating the local buckling in the compression area, the waved connection was able to reduce the plastic strain values significantly.

The most critical point is a point with the highest strain values per displacement of the fault, and its position is shown in Figure 7. Plastic strain values at these points relative to the fault displacement have been drawn in a coordinate system for each of the straight pipes and the pipes with a waved connection in the compressive area, and the tensile area has been drawn in a coordinate system, and the results are compared with each other.

According to Figure $7(\mathrm{a})$, the plastic behavior of the straight pipe in the compressive area under the displacement of the $25 \mathrm{~cm}$ fault and the tensile area under the displacement of about $40 \mathrm{~cm}$ enters the plastic area. It also enters the buckling area at a displacement of $38 \mathrm{~cm}$, in which case, the plastic strain values increase sharply. Thus, the maximum values of plastic strain due to $120 \mathrm{~cm}$ fault displacement in the tensile and compressive areas are equal to 0.03 and 0.3 , respectively. Local buckling is the reason for the fact that the plastic strain values are ten times higher in the compressive area than in the tensile area. On the other hand, in Figure 7(b), both critical points in tension and compression enter the plastic area in the same displacement of the $20 \mathrm{~cm}$ fault and, of course, with increasing fault displacement, have less growth than the straight pipe. With a $120 \mathrm{~cm}$ displacement, the plastic strain values of the critical points of tension and compression reach 0.06 and 0.04 , respectively. Thus, by comparing the above results, the waved connection has increased the plastic strain values at critical points compared with the straight pipe by 0.03 and decreased by 0.26 in the compressive and tensile areas, respectively.

According to Figure 7, it is clear that the highest values of plastic strain at critical points for straight pipe and waved pipe are in the compressive and tensile areas, respectively. Based on the comparison of plastic strain values in the most critical points of straight pipe and pipe with waved connection, it can be said that the waved connection has been able to reduce the strain values by $87 \%$ significantly. Wave connection has been able to reduce the plastic strain values well and limit the stress distribution areas. Then, by considering two waved connections (double connection) next to each other, the pipe's performance is evaluated, as shown in Figure 8 .

In critical areas, two consecutive waved connections are installed. The plastic strain values in the tensile and compressive areas are compared with each other and with the single connection mode (Figures 9 and 10).

According to Figure 9, it can be seen that the plastic strain values in the tensile area are distributed in two parts, 

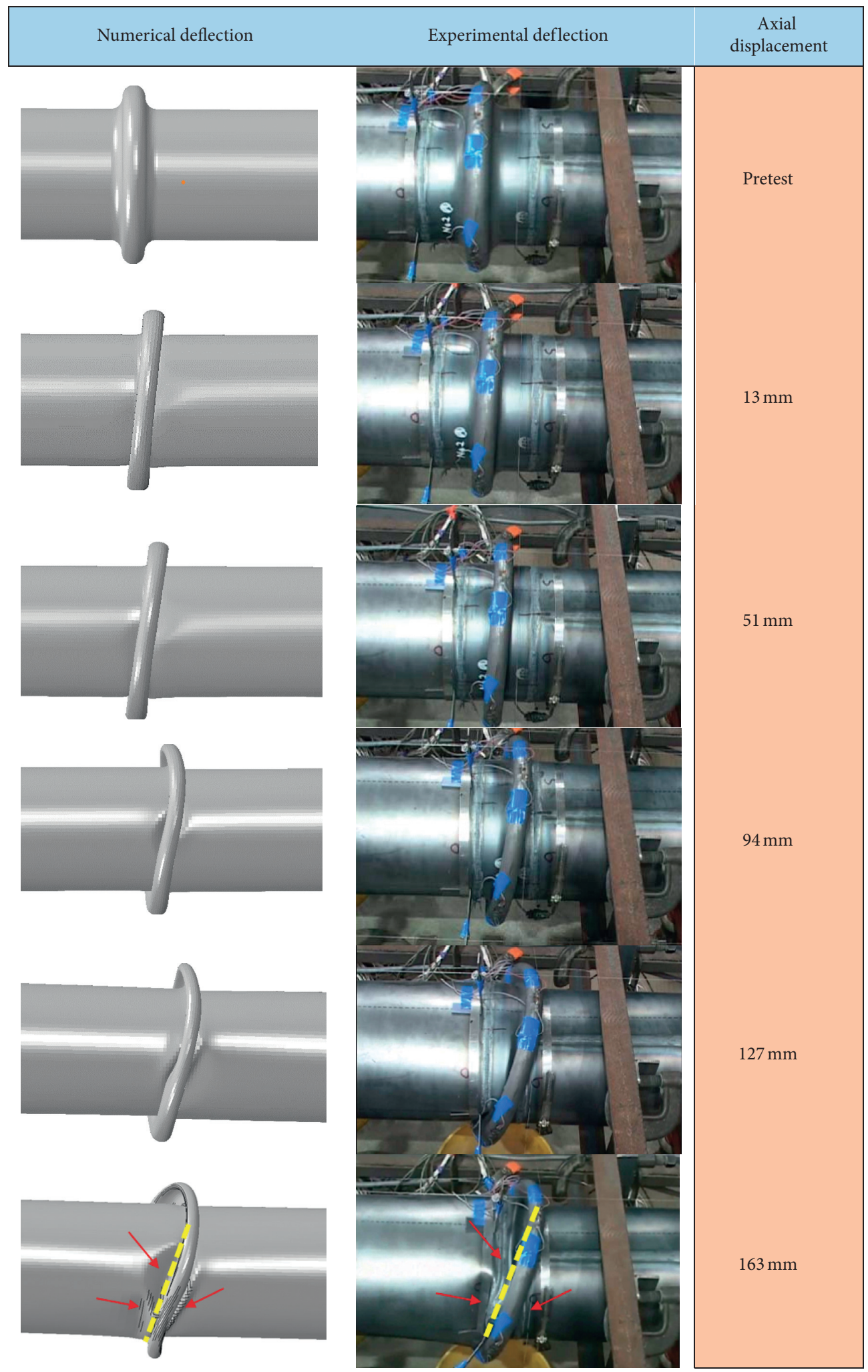

Figure 3: Comparison between deformed pipes of the experimental [34] and numerical models.

but in the compression area, the second connection does not enter the plastic area. The plastic strain values in Figures 9 and 10 are compared to understand better the double connection's performance beside the single connection.
As mentioned, the tensile area of the double connection is divided into two parts. By comparing the first connection with the single connection, the first, second, and third peaks of the diagram have a $10 \%, 33 \%$, and $9 \%$ reduction in plastic 


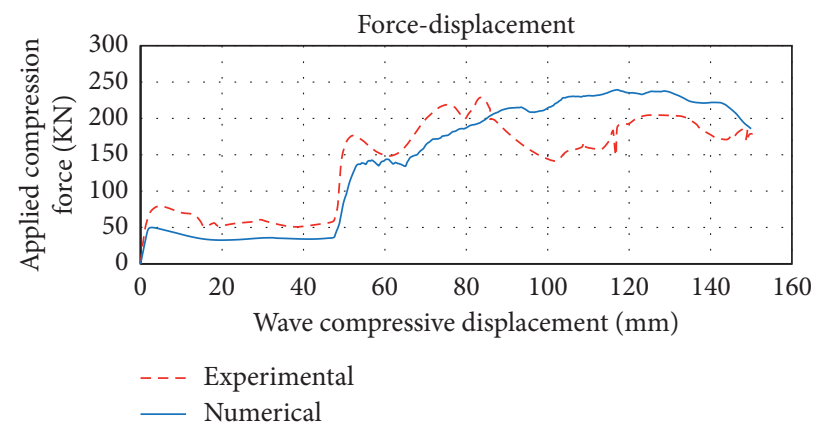

Figure 4: Comparison of axial force-displacement results of experimental and numerical models.

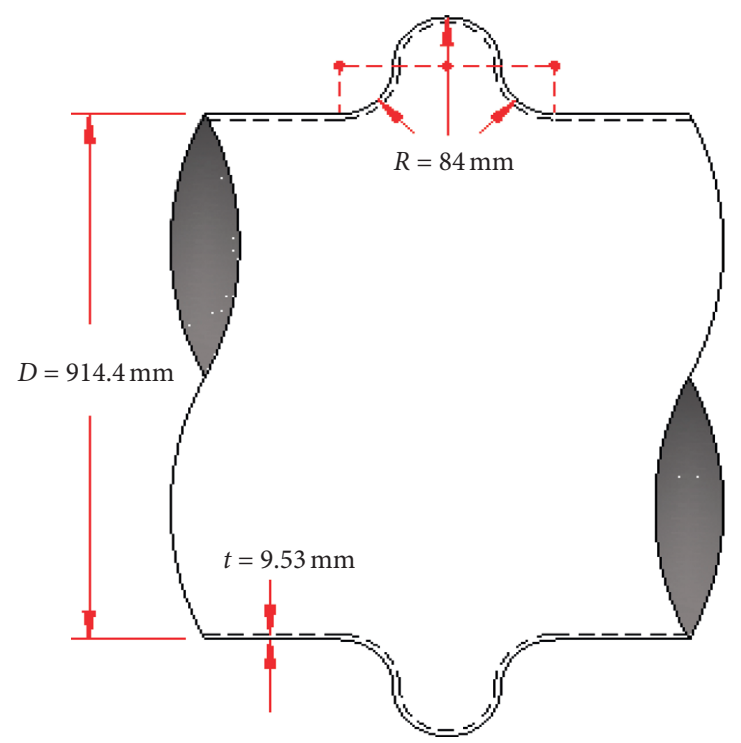

FIGURE 5: Geometric properties of waved connection used in the numerical model.

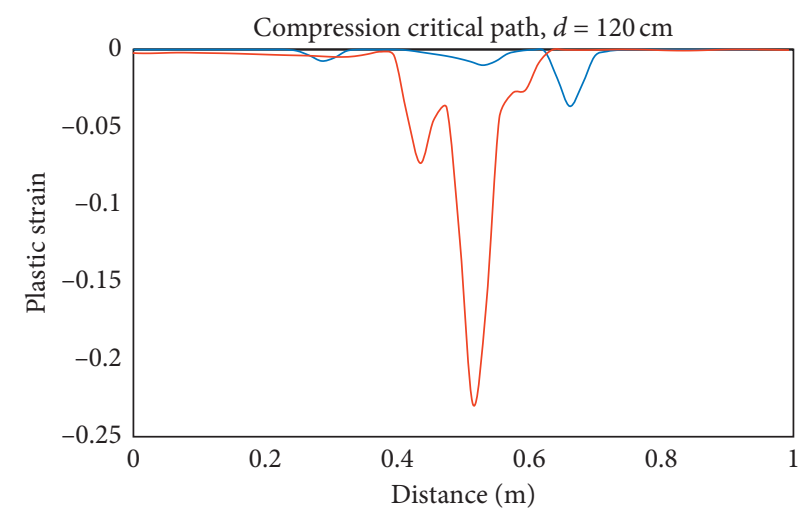

Waved pipe Straight pipe

(a)

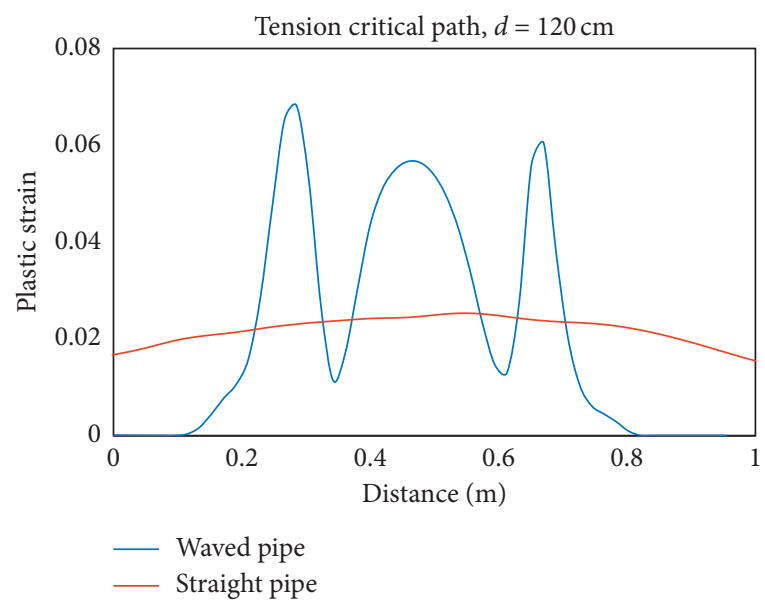

(b)

Figure 6: Comparison of plastic strain in tension and compression critical areas. 


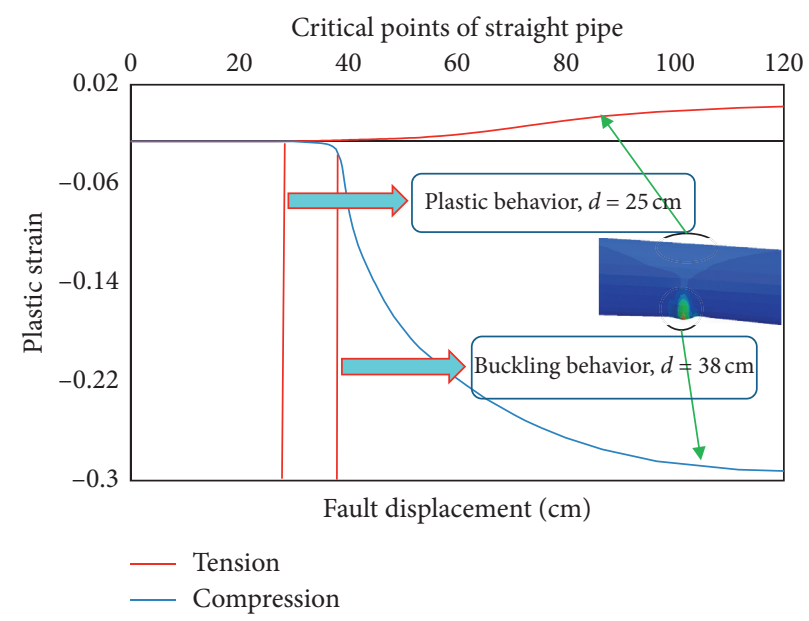

(a)

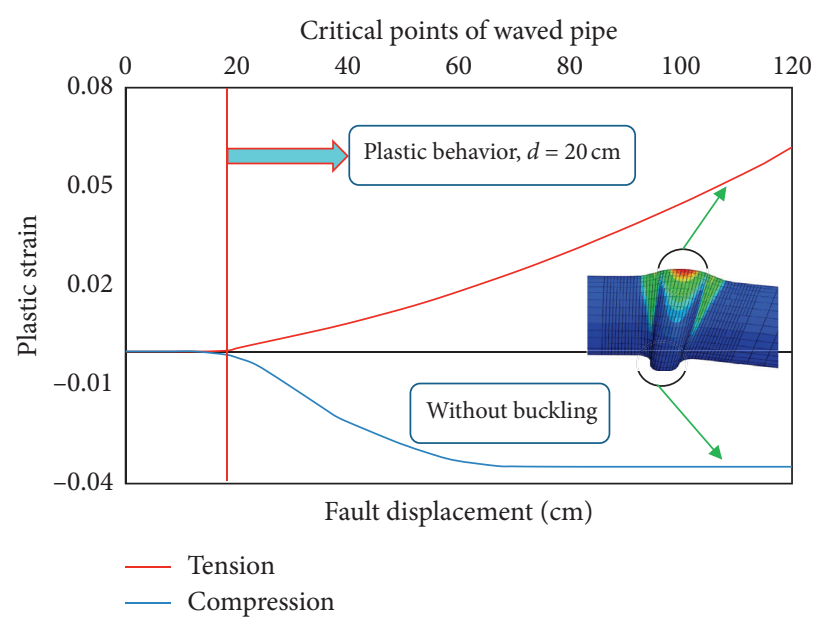

(b)

FIGURE 7: Comparison of plastic strain results in critical point. (a) Straight pipe. (b) Waved pipe.

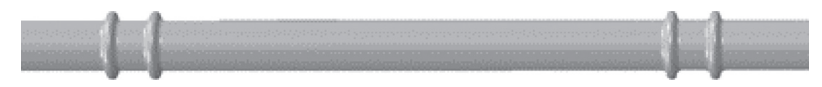

(a)

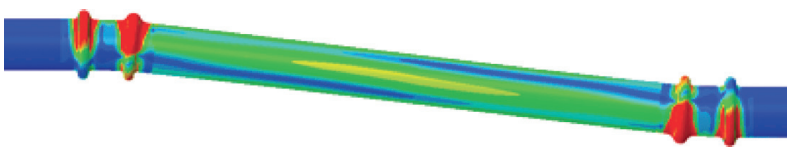

(b)

Figure 8: Von Mises contour of pipeline with double connection. (a) Before displacement. (b) After displacement.

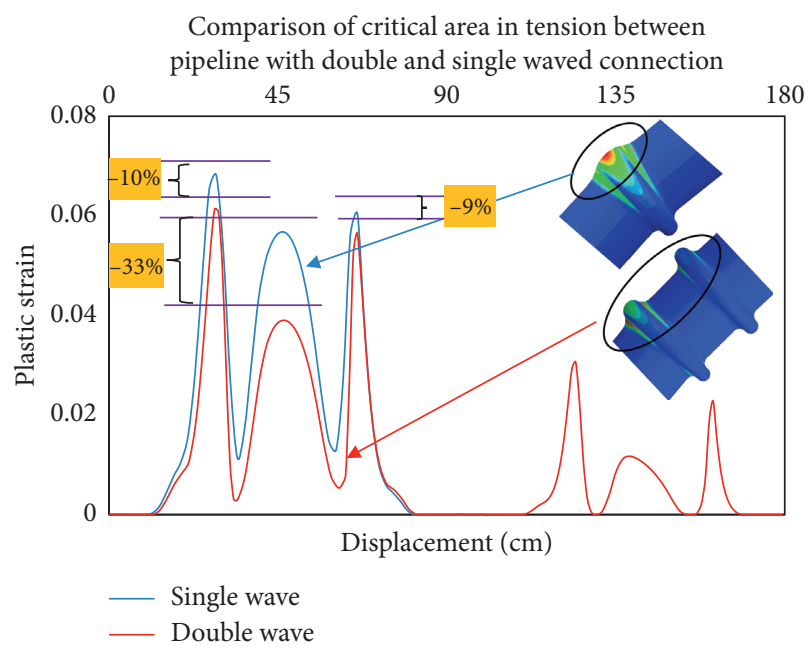

FIGURE 9: Contour of plastic strain on the critical area in tension.

strain, respectively. This reduction confirms the proper addition of the number of connections in different pipe areas that can improve its performance.

By comparing the plastic strain values in the compression areas of the double connection and the single connection, significant changes can be seen in reducing the plastic strain values. As mentioned, in the double connection, the second connection did not enter the plastic area, but the stress distribution in the two connections was such that the plastic strain values in the two double connections were sharply reduced. This decrease in the first, second, and third peaks was

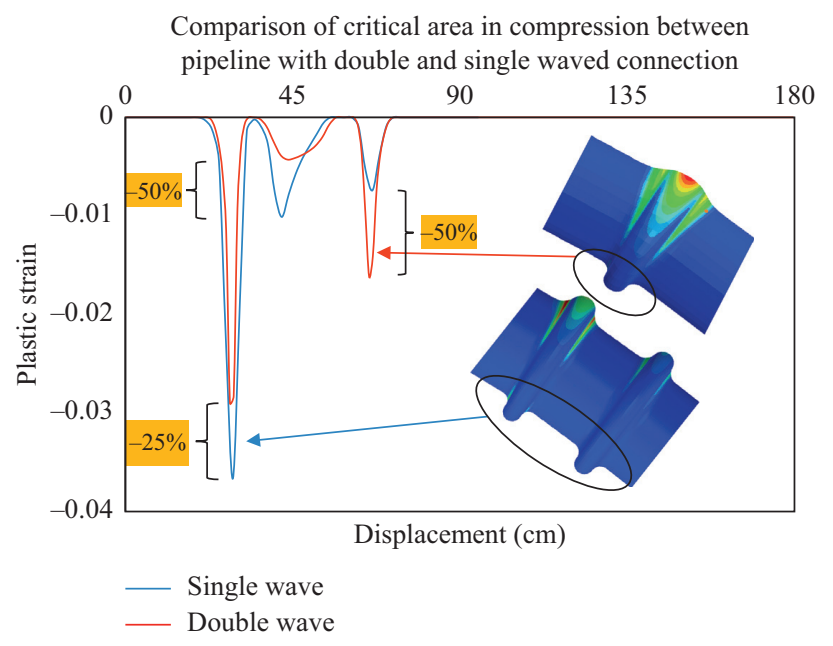

FIgURE 10: Contour of plastic strain on the critical area in compression.

equal to $25 \%, 50 \%$, and $50 \%$, respectively. The results show a significant improvement in the double waved connection's performance compared to the single connection.

\section{Conclusion}

In this paper, one solution to reduce the risks of fault displacement on the pipe's performance is investigated. The solution is to use a waved connection in the pipes. This connection was first proposed in 2017 by Packer Loan, and 
its laboratory model is based on large axial deformations. Since steel pipes can withstand many strains after yielding, the plastic strain is considered the main output of the present paper in tensile and compressive critical areas. Its values have been compared in two straight pipes and pipes waved connection.

The double connection's tensile area is divided into two parts by comparing the pipe's performance with a double waved connection and a single waved connection. By comparing its first connection with a single connection, the first, second, and third peaks of the diagram are reduced by $10 \%$, $33 \%$, and $9 \%$, respectively, in their plastic strain, which confirms that a proper increase in the number of connections in different areas of the pipe can improve its performance.

By comparing the plastic strain values in the double connection's compression areas and the single connection, very significant changes can be seen in reducing the plastic strain values. This decrease in the first, second, and third peaks was equal to $25 \%, 50 \%$, and $50 \%$, respectively. The results show a significant improvement in the double wave connection's performance compared to the single connection. It should be noted that this connection is simple and low cost in construction; besides, it is easily applicable, and according to its optimal performance, it will be an attractive option for employers of oil and gas companies. In addition to being inexpensive and straightforward to build, this connection is easy to implement.

\section{Data Availability}

The data used to support the findings of this study are available from the corresponding author upon request.

\section{Conflicts of Interest}

The authors declare that there are no conflicts of interest.

\section{References}

[1] N. M. Newmark and W. J. Hall, "Pipeline design to resist large fault displacement," in Proceedings of US national conference on earthquake engineering, Ann Arbor, Michigan, June 1975.

[2] R. Kennedy, "Fault crossing design for buried gas oil pipelines," American Society of Mechanical Engineers, PVP.vol. 77, pp. 1-9, 1983.

[3] R. P. Kennedy, A. Chow, and R. A. Williamson, "Fault movement effects on buried oil pipeline," Transportation Engineering Journal of the American Society of Civil Engineers, vol. 103, no. 5, pp. 617-633, 1977.

[4] L. R.-L. Wang and Y.-H. Yeh, "A refined seismic analysis and design of buried pipeline for fault movement," Earthquake Engineering \& Structural Dynamics, vol. 13, no. 1, pp. 75-96, 1985.

[5] E. Vougioukas, C. Theodossis, and P. Carydis, "Seismic analysis of buried pipelines subjected to vertical fault movement," Lifeline Earthquake Engineering, pp. 432-441, 1979.

[6] M. MaCaffrey, "Buried pipeline response to reverse faulting during the 1971 San Fernando Earthquake," American Society of Mechanical Engineers, PVP, vol. 77, pp. 151-159, 1983.
[7] T. Desmond, M. Power, C. Taylor, and R. Lau, Behavior of Large-Diameter Pipelines at Fault Crossings, American Society of Civil Engineers, New York, NY, USA, 1995.

[8] L. Wang, "Parametric study of buried pipelines due to large fault movement, ASCE," Technical Coucil on Lifeline Earthquake Engineering, vol. 6, pp. 152-159, 1995.

[9] S. Takada, N. Hassani, and K. Fukuda, "A new proposal for simplified design of buried steel pipes crossing active faults," Earthquake Engineering \& Structural Dynamics, vol. 30, no. 8, pp. 1243-1257, 2001.

[10] D. K. Karamitros, G. D. Bouckovalas, and G. P. Kouretzis, "Stress analysis of buried steel pipelines at strike-slip fault crossings," Soil Dynamics and Earthquake Engineering, vol. 27, no. 3, pp. 200-211, 2007.

[11] O. V. Trifonov, "Numerical stress-strain analysis of buried steel pipelines crossing active strike-slip faults with an emphasis on fault modeling aspects," Journal of Pipeline Systems Engineering and Practice, vol. 6, no. 1, Article ID 04014008, 2015.

[12] O. V. Trifonov and V. P. Cherniy, "A semi-analytical approach to a nonlinear stress-strain analysis of buried steel pipelines crossing active faults," Soil Dynamics and Earthquake Engineering, vol. 30, no. 11, pp. 1298-1308, 2010.

[13] M. Bouatia, R. Demagh, and Z. Derriche, "Structural behavior of pipelines buried in expansive soils under rainfall infiltration (Part I: transverse behavior)," Civil Engineering Journal, vol. 6, no. 9, pp. 1822-1838, 2020.

[14] W. Chettah, Investigation des propriétés minéralogiques et géomécaniques des terrains en mouvement dans la ville de Mila "Nord-Est d'Algérie », Thèse de Magistère, University of Batna 1 Hadj Lakhdhar, Batna, Algérie, 2009.

[15] A. Djamel, A. Benaissa, A. Hammadi, and M. Bouassida, "Clay and marl formation susceptibility in Mila Province, Algeria," Geotechnical and Geological Engineering, vol. 28, no. 6, pp. 805-813, 2010.

[16] A. Haghollahi and H. Ahmadi, "Cyclic behavior of steel beamto-column moment connections using different sizes of flange plates and reinforced by a single rib plate," Civil Engineering Journal, vol. 4, no. 1, pp. 138-150, 2018.

[17] L. Xu and M. Lin, "Analysis of buried pipelines subjected to reverse fault motion using the vector form intrinsic finite element method," Soil Dynamics and Earthquake Engineering, vol. 93, pp. 61-83, 2017.

[18] E. Uckan, B. Akbas, J. Shen, W. Rou, F. Paolacci, and M. O’Rourke, “A simplified analysis model for determining the seismic response of buried steel pipes at strike-slip fault crossings," Soil Dynamics and Earthquake Engineering, vol. 75, pp. 55-65, 2015.

[19] E. C. F. Standardization, Eurocode 8: Design of Structures for Earthquake Resistance-Part 4: Silos, Tanks and Pipelines, 2006.

[20] A. L. Alliance, "Guidelines for the design of buried steel pipe," American Society of Civil Engineers, 2001.

[21] P. Vazouras, S. A. Karamanos, and P. Dakoulas, "Mechanical behavior of buried steel pipes crossing active strike-slip faults," Soil Dynamics and Earthquake Engineering, vol. 41, pp. 164-180, 2012.

[22] J. Zhang, Z. Liang, and C. J. Han, "Buckling behavior analysis of buried gas pipeline under strike-slip fault displacement," Journal of Natural Gas Science and Engineering, vol. 21, pp. 921-928, 2014.

[23] S. R. Reid, "Plastic deformation mechanisms in axially compressed metal tubes used as impact energy absorbers," 
International Journal of Mechanical Sciences, vol. 35, no. 12, pp. 1035-1052, 1993.

[24] I. Tutuncu, Compressive Load and Buckling Response of Steel Pipelines during Earthquakes, 2002.

[25] B. Wham, C. Pariya-Ekkasut, C. Argyrou et al., "Large axial deformation performance of steel pipeline designed for fault crossings," in Proceedings of the Pipelines 2017, Phoenix, Arizona, August 2017, https://www.researchgate.net/deref/ http\%3A\%2F\%2Fdx.doi.org\%2F10.1061\%2F9780784480878. 010.

[26] S. Ghods, A. Kheyroddin, M. Nazeryan, S. M. Mirtaheri, and M. Gholhaki, "Nonlinear behavior of connections in RCS frames with bracing and steel plate shear wall," Steel and Composite Structures, vol. 22, no. 4, pp. 915-935, 2016.

[27] N. Hassani, S. M. S. Kolbadi, M. R. Shiravand, and J. H. Golafshani, "Impact of geometric pattern corrosion on limit failure pressure of buried gas pipelines," Structural Engineering and Mechanics, vol. 59, no. 5, pp. 795-802, 2016.

[28] F. C. Bardi and S. Kyriakides, "Plastic buckling of circular tubes under axial compression-part I: Experiments," International Journal of Mechanical Sciences, vol. 48, no. 8, pp. 830-841, 2006.

[29] S. Kyriakides and J. G.T., "Bifurcation and localization instabilities in cylindrical shells under bending-I. Experiments," International Journal of Solids and Structures, vol. 29, no. 9, pp. 1117-1142, 1992.

[30] S. A. Karamanos and J. L. Tassoulas, "Tubular members. II: local buckling and experimental verification," Journal of Engineering Mechanics, vol. 122, no. 1, pp. 72-78, 1996.

[31] H. Yun and S. Kyriakides, "On the beam and shell modes of buckling of buried pipelines," Soil Dynamics and Earthquake Engineering, vol. 9, no. 4, pp. 179-193, 1990.

[32] N. H. SMS Kolbadi, S. M. S. Kolbadi, and M. R. Shiravand, "Effect of ground motions on nonlinear seismic behavior of corroded buried gas pipeline," American Journal of Civil Engineering, vol. 3, no. 2, pp. 9-13, 2015.

[33] M. O'Rourke and X. Liu, Seismic Design of Buried and Offshore pipelines, Multidisciplinary Center for Earthquake Engineering Research, Buffalo, New York, USA, 2012.

[34] M. Hetenyi, Beams on Elastic Foundations, p. 94, The University of Michigan Press, Ann Arbor, MI, USA, 1946.

[35] L. Brazier, "On the flexure of thin cylindrical shells and other "thin" sections," Proceedings of the Royal Society of London. Series A, Containing Papers of a Mathematical and Physical Character, vol. 116, no. 773, pp. 104-114, 1927.

[36] S. P. Timoshenko and J. M. Gere, Theory of Elastic Stability, Courier Corporation, Chelmsford, MA, USA, 2009.

[37] L. Hu and S. Yuan, "Plastic deformation analysis of thinwalled tube bending under internal pressure," Journal of Mechanical Engineering, vol. 48, no. 14, pp. 78-83, 2012.

[38] S. Joshi, A. Prashant, A. Deb, and S. K. Jain, "Analysis of buried pipelines subjected to reverse fault motion," Soil Dynamics and Earthquake Engineering, vol. 31, no. 7, pp. 930-940, 2011.

[39] A. Anon, B31. 8-2012, Gas Transmission and Distribution Piping Systems, p. 12, American Society of Mechanical Engineers (ASME), New York, NY, USA, 2013.

[40] ASME, Pipeline Transportation Systems for Liquid Hydrocarbons and Other Liquids, American Society of Mechanical Engineers (ASME), New York, NY, USA, 2002. 